\title{
Treatment trends in early-stage lung cancer in the United States, 2004 to 2013: A time-trend analysis of the National Cancer Data Base
}

\author{
Kathryn E. Engelhardt, MD, MS, a,b,c Joseph M. Feinglass, PhD, ${ }^{\mathrm{d}}$ Malcolm M. DeCamp, MD, ${ }^{\mathrm{e}, \mathrm{f}}$ \\ Karl Y. Bilimoria, MD, MS, ${ }^{\mathrm{a}, \mathrm{b}, \mathrm{f}}$ and David D. Odell, MD, MMSc ${ }^{\mathrm{a}, \mathrm{b}, \mathrm{e}, \mathrm{f}}$
}

\section{ABSTRACT}

Objective: The study objective was to evaluate trends in the use of surgical therapy for patients with early-stage (IA-IIA) non-small cell lung cancer when stereotactic ablative radiotherapy was introduced in the United States.

Methods: Patients with clinical stage IA to IIA non-small cell lung cancer diagnosed from January 1, 2004, to December 31, 2013, were identified in the National Cancer Data Base. The Cochran-Armitage trend test was used to evaluate the change in the proportion of patients undergoing surgery over time. Logistic regression was used to identify the factors associated with receipt of surgery compared with radiation.

Results: Of 200,404 eligible patients from 1235 hospitals, $79.8 \%(n=159,943)$ underwent surgery. For all stages combined, the rate of surgery decreased from $83.9 \%$ in 2004 to $75.1 \%$ in $2013(P<.0001)$, with the largest decrease seen in patients with stage IIA: stage IA $86.5 \%$ to $77.1 \%(P<.0001)$; stage IB $79.6 \%$ to $71.5 \%(P<.0001)$; and stage IIA $94.7 \%$ to $70.3 \%(P<.001)$. Patients were more likely to undergo surgery if they were younger and white, had higher income, or had private or Medicare insurance.

Conclusions: From 2004 to 2013, there was an overall decrease in the use of surgical therapy for lung cancer in early-stage disease. Because resection remains the standard of care for most patients with early-stage disease, these data suggest a potentially significant quality gap in the treatment of patients with non-small cell lung cancer. (J Thorac Cardiovasc Surg 2018;156:1233-46)

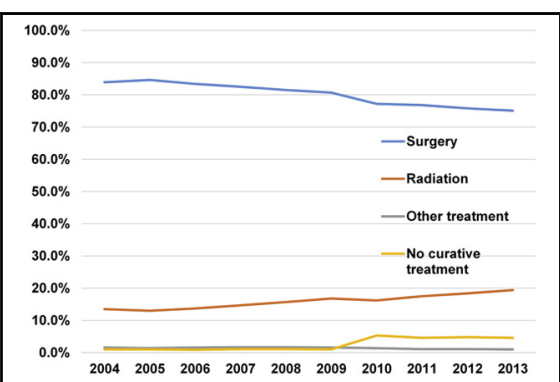

National trend in management of stage IA to $\| A$ NSCLC from 2004 to 2013.

\section{Central Message}

The past decade saw a decreased use of surgica therapy for lung cancer in early-stage disease even though resection remains the standard of care for most of these patients.

\section{Perspective}

The recent decline in use of surgical therapy for early-stage NSCLC demands further evaluation of patient, physician, and system factors influencing treatment choice. Determining the cause of this quality gap requires innovative research methodology because of limitations of currently available datasets.

See Editorial Commentary page 1247.
Lung cancer is the leading cause of cancer-related death in the United States with 224,390 new cases and 158,080 deaths estimated in $2016 .{ }^{1}$ For patients with early-stage (stage IAIIA) non-small cell lung cancer (NSCLC), surgical resection

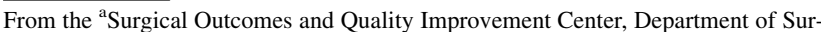
gery and Center for Healthcare Studies, Feinberg School of Medicine, Divisions of ${ }^{\mathrm{d}}$ General Internal Medicine and Geriatrics and ${ }^{\mathrm{e}}$ Thoracic Surgery, Northwestern University Feinberg School of Medicine, Chicago, Ill; ${ }^{\mathrm{b}}$ Northwestern Institute for Comparative Effectiveness Research in Oncology, Chicago, Ill; ${ }^{\mathrm{c}}$ Department of Surgery, Medical University of South Carolina, Charleston, SC; and ${ }^{\mathrm{f}}$ Robert H. Lurie Comprehensive Cancer Center, Northwestern University Feinberg School of Medicine, Chicago, Ill.

This work is supported by the National Cancer Institute of the National Institutes of Health under Award Number K07CA216330, the Northwestern Institute for Comparative Effectiveness Research in Oncology postdoctoral fellowship, and the American Association for Thoracic Surgery Graham Foundation Oz Lemole research grant.
}

provides the best chance for cure. ${ }^{2}$ However, because of the etiology of lung cancer, many patients have age- and smoking-related comorbidities, contributing to increased surgical risk. Although some of these patients are clearly

\footnotetext{
Read at the 97th Annual Meeting of The American Association for Thoracic Surgery, Boston, Massachusetts, April 29-May 3, 2017.

Received for publication April 30, 2017; revisions received March 14, 2018; accepted for publication March 22, 2018.

Address for reprints: David D. Odell, MD, MMSc, Surgical Outcomes and Quality Improvement Center, Department of Surgery Feinberg School of Medicine, Northwestern University, 633 N St Clair St, 20th Floor, Chicago, IL 60611 (E-mail dodell@nm.org). 0022-5223/\$36.00

Copyright $\odot 2018$ Published by Elsevier Inc. on behalf of The American Association for Thoracic Surgery

https://doi.org/10.1016/j.jtcvs.2018.03.174
} 


\section{Abbreviations and Acronyms}

$\mathrm{CoC}=$ Commission on Cancer

$\mathrm{NCDB}=$ National Cancer Data Base

NSCLC $=$ non-small cell lung cancer

SABR $=$ stereotactic ablative radiotherapy

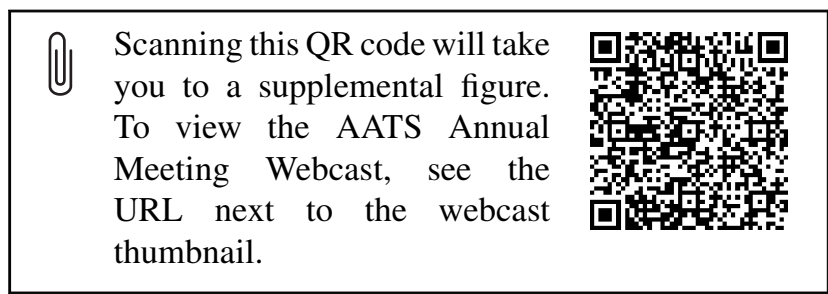

not surgical candidates because of medical comorbidity, there remains a large cohort for whom the decision to operate is not clear-cut. Because of the aging US population and current screening guidelines supporting the use of computed tomography in groups at high risk for lung cancer, the number of potentially resectable lung cancers in these moderate-risk patients is expected to increase.

In the past decade, stereotactic ablative radiotherapy (SABR) has emerged as an alternate to surgical therapy for high medical risk patients with localized disease. SABR delivers focused external beam radiation at ablative doses in 1 to 5 fractions. $^{3}$ Treatment is completed in an outpatient setting over approximately 2 weeks. The benefits over traditional radiation therapy include a focused treatment target, minimizing radiation-induced damage to adjacent parenchyma, and a shorter treatment schedule thereby reducing inconvenience to the patient. ${ }^{4}$ Survey data suggest approximately half of radiation oncologists were routinely using SABR for patients with NSCLC by 2008. ${ }^{5}$ Multiple analyses, including meta-analyses and Markov decision models, have suggested outcomes comparable to resection in medically inoperable patient populations with regard to locoregional control, disease-free survival, and overall survival., ${ }^{4,6-11}$ However, randomized clinical trials evaluating SABR for potentially operable patients have failed to accrue patients and have closed early (STARS trial [NCT00840749], ROSEL trial [NCT00687986], and ACOSOG Z4099 trial [NCT01336894]). ${ }^{12-14}$ When treatment technology evolves more rapidly than randomized clinical trials can be completed, treatment trends in the community do not always reflect the available level 1 data. ${ }^{15}$

Despite current evidence, little is known about the effect that the introduction of SABR has had on the use of surgery for early-stage lung cancer. By using the National Cancer Data Base (NCDB), we sought to determine the following for patients treated in the United States: (1) the trend in the rate of surgical therapy, as well as alternate treatment modalities, for patients with early-stage (IA-IIA) NSCLC; (2) the reported reasons for not receiving surgery, as documented in the NCDB; and (3) the identification of factors associated with receipt of surgery compared with radiation.

\section{MATERIALS AND METHODS Data Source}

Data were obtained from the NCDB, a joint program of the American College of Surgeons and American Cancer Society. The largest cancer registry in the world, the NCDB is estimated to capture approximately $70 \%$ of all new cancer diagnoses in the United States and Puerto Rico, including $82 \%$ of lung cancer diagnoses. ${ }^{16}$ Data are collected by Certified Tumor Registrars who undergo extensive training and are audited to ensure accuracy of the database. Hospital and patient identity are protected and not included in the Participant Use File. Data released in the Participant Use File are in compliance with the privacy requirements of the Health Information Portability and Accountability Act. The Institutional Review Board at Northwestern University determined this study was exempt because it uses publicly available de-identified data.

\section{Patient Selection}

The 2014 NCBD Participant Use File was queried to identify patients diagnosed with NSCLC from January 1, 2004, to December 31, 2013. We included all patients with a clinical or pathologic stage of IA to IIA NSCLC, as determined by the American Joint Committee on Cancer 6th or 7th Edition Cancer Staging Manual, which do not differ with respect to staging for our patient population of focus. ${ }^{17}$ Patients with clinical N1 disease were excluded because they would not be candidates for SABR. If there were discrepancies between clinical and pathologic stage determination, we preferentially used clinical stage to reflect the information available at the time a treatment decision was made. We excluded patients with missing treatment data $(n=29,277,2.5 \%)$. In addition, patients with previous cancers, recurrent cancer, or possible metastatic disease from an extrathoracic primary tumor were excluded from the analysis because these groups were thought to represent a biologically distinct disease process $(\mathrm{n}=92,450 ; 7.9 \%)$. Trends in care were analyzed for the entire patient cohort. Regression modeling focused on the most recent 3 years to most closely reflect decision making in current use patterns.

\section{Treatment Modalities}

We grouped eligible patients by the primary treatment modality used for their primary tumor. Surgical patients include those who underwent sublobar resection (including segmentectomy and wedge resection), lobar or bilobar resection, or pneumonectomy. We did not differentiate between the various radiation protocols because the ideal protocol for SABR is still being defined, protocols varied when this modality was introduced, and, as a result, abstraction may have been inconsistent. ${ }^{9}$ Thus, patients coded as receiving radiation therapy included both SABR and any other form of radiation therapy. It should be emphasized that throughout this article "radiation" refers to all forms of radiation therapy where "SABR" will refer specifically to stereotactic ablative radiotherapy. The "Other" category includes patients who were documented to have received treatment with curative intent, for example, radiofrequency ablation or doublet chemotherapy. The patients included in the "No curative treatment" group included patients who received single-agent chemotherapy regimens, hormonal therapy, or immunotherapy, as well as patients undergoing active surveillance.

\section{Statistical Analysis}

In the unadjusted analysis, we performed a Cochran-Armitage trend test for the proportion of patients who received surgery for each stage category from 2004 to 2013. Each year was considered as a separate cohort to maintain 
the granularity of data available. To compare practice patterns for alternate treatment before and after SABR was widely used in $2008,{ }^{5}$ we created two 2-year cohorts: patients diagnosed with NSCLC from 2004 to 2005 and 2012 to 2013. For the nonsurgical group, we generated descriptive statistics for the alternate treatment modalities during the study time period, as well as the reason recorded for not receiving surgical therapy. We then estimated a multivariable logistic regression model with receipt of surgery (vs radiation) as our outcome variable to identify factors associated with the decision between ultimate receipt of surgery and radiation. We included patients diagnosed between 2011 and 2013 to reflect the most current decision-making practices available. Patient clustering by treating facility was accounted for in our model with the robust covariance matrix estimator (unidimensional clustering) because of the large number of treating facilities $(n=1235)$.

\section{Covariate Selection}

We chose covariates a priori on the basis of the identification in the literature of factors associated with disparities in surgical care and forced these into our model. ${ }^{2,18-22}$ These factors included year (modeled as a categoric variable), tumor characteristics (histology and stage), patient-level factors (age, race/ethnicity, sex, median income, median education level, insurance status, and modified Charlson-Deyo comorbidity score ${ }^{23}$ ), and hospital-level factors (a combined variable that takes into account both the hospital volume and the academic status of the hospital). Because histology is known to affect survival and therefore may affect the decision to operate, we included histology as a categoric variable with 3 groups: adenocarcinoma, squamous cell carcinoma, or other non-small cell carcinoma. All patients in the NCDB have documented histology; thus, patients who are treated without a histologic diagnosis documentation were not included in this analysis. We grouped patients according to the American Joint Committee on Cancer clinical stage recorded in the NCDB. Age was included as a continuous variable. Race and ethnicity were grouped into 4 categories as defined by the Commission on Cancer $(\mathrm{CoC})$ : nonHispanic white, non-Hispanic African-American, Hispanic, and other. Race and ethnicity were abstracted from patient charts by NCDB abstractors; because each hospital may vary with regard to how patient race and ethnicity were entered into charts, it was not possible to determine whether these data were self-reported or not. Patients were grouped into quartiles for income and education derived from census data for their ZIP code, as defined by the CoC. Insurance status was dichotomized into 2 groups presumed to represent lower and higher socioeconomic status: Medicaid and uninsured versus all others. ${ }^{24} \mathrm{~A}$ modified Charlson-Deyo comorbidity score was included as a categoric variable as defined by the $\mathrm{CoC}$ : zero, 1 , and 2 or more. Facility characteristics were accounted for in the model with a variable representing volume and academic status. For this variable, "high volume" refers to hospitals in the top quartile for number of unique patients treated for lung cancer, averaged over the study time period. Academic hospitals were defined by the $\mathrm{CoC}$ as having 500 or more newly diagnosed cancer types per year and offering graduate medical education programs in greater than 4 disciplines. We assessed for and did not find a significant interaction between insurance status and income level, between facility and income level, or between facility and insurance status. Therefore, no interaction term was included in our final model. Analyses were performed using STATA v14 (StataCorp LP, College Station, Tex) and SAS v9.4 (SAS Institute Inc, Cary, NC) statistical software.

\section{RESULTS}

\section{Baseline Patient Data}

We analyzed 200,404 eligible patients (Figure 1). Patients undergoing surgery were younger and white, and were treated at high-volume academic centers (Table 1). Of note, patients who received radiation had fewer comorbid conditions documented.

\section{Time Trend With Single-Year Cohorts}

Overall, $79.8 \%(n=159,943)$ of patients underwent surgery. For all stages combined, the rate of surgery decreased from $83.9 \%$ in 2004 to $75.1 \%$ in $2013(P<.0001)$, with the largest decrease seen in patients with stage IIA: stage IA $86.5 \%$ to $77.1 \%(P<.0001)$; stage IB $79.6 \%$ to $71.5 \%$ $(P<.0001)$; and stage IIA $94.7 \%$ to $70.3 \%(P<.001)$ (Figure 2). The proportion of early-stage lung cancers compared with the overall number of lung cancer diagnoses is shown in Figure E1.

\section{Alternate Treatment Before and After Stereotactic Ablative Radiotherapy Availability}

Of nonsurgical patients $(\mathrm{n}=40,461)$, the majority were treated with radiation $(\mathrm{n}=32,244 ; 79.7 \%)$, and $13.4 \%$ of patients $(\mathrm{n}=5431)$ received no curative treatment. A minority $(\mathrm{n}=2786 ; 6.9 \%)$ of nonsurgical patients were treated with some other modality, including radiofrequency ablation, chemotherapy, and experimental methods.

Comparing the first 2 years and last 2 years of the study time period (Table 2), the proportion of patients receiving radiation therapy increased by $5.6 \%$ (95\% confidence interval $[\mathrm{CI}], 5.1-6.1)$. Comparing the same 2 groups of patients, the proportion of patients receiving surgical therapy decreased by $8.8 \%$ (95\% CI, 8.3-9.4), and the proportion of patients receiving no curative treatment increased by $3.7 \%$ (95\% CI, 3.5-3.9) (absolute percentages).

\section{Reason for Not Receiving Surgery}

The most common reason recorded for not undergoing surgery was that an alternate treatment was recommended as first-line therapy $(n=27,986 ; 69.2 \%$ of patients in the nonsurgical cohort). Approximately $20.5 \%(n=8283)$ of patients were noted to not be surgical candidates because of patient risk factors (eg, medical comorbidities or advanced age $)$. We found $4.6 \%(n=1849)$ of patients did not receive recommended surgery because the patient or patient's family refused. In $0.7 \%$ of patients $(n=283)$, surgery was recommended but not performed for unknown reasons, and in $1.9 \%$ of patients $(\mathrm{n}=764)$, it was unknown if surgery was recommended.

Comparing the first 2 years and last 2 years of the study time period, the proportion of patients and families who refuse a recommended operation increased from $3.7 \%$ to $5.3 \%(P<.0001)$. All other reasons for refusal did not change over the study time period.

\section{Adjusted Analysis}

In our multivariable logistic regression model (Table 3), earlier year of diagnosis was significantly associated with receiving surgical therapy compared with radiation. $\mathrm{Pa}$ tients were more likely to undergo surgery if they were younger and white, lived in higher income areas, or had 


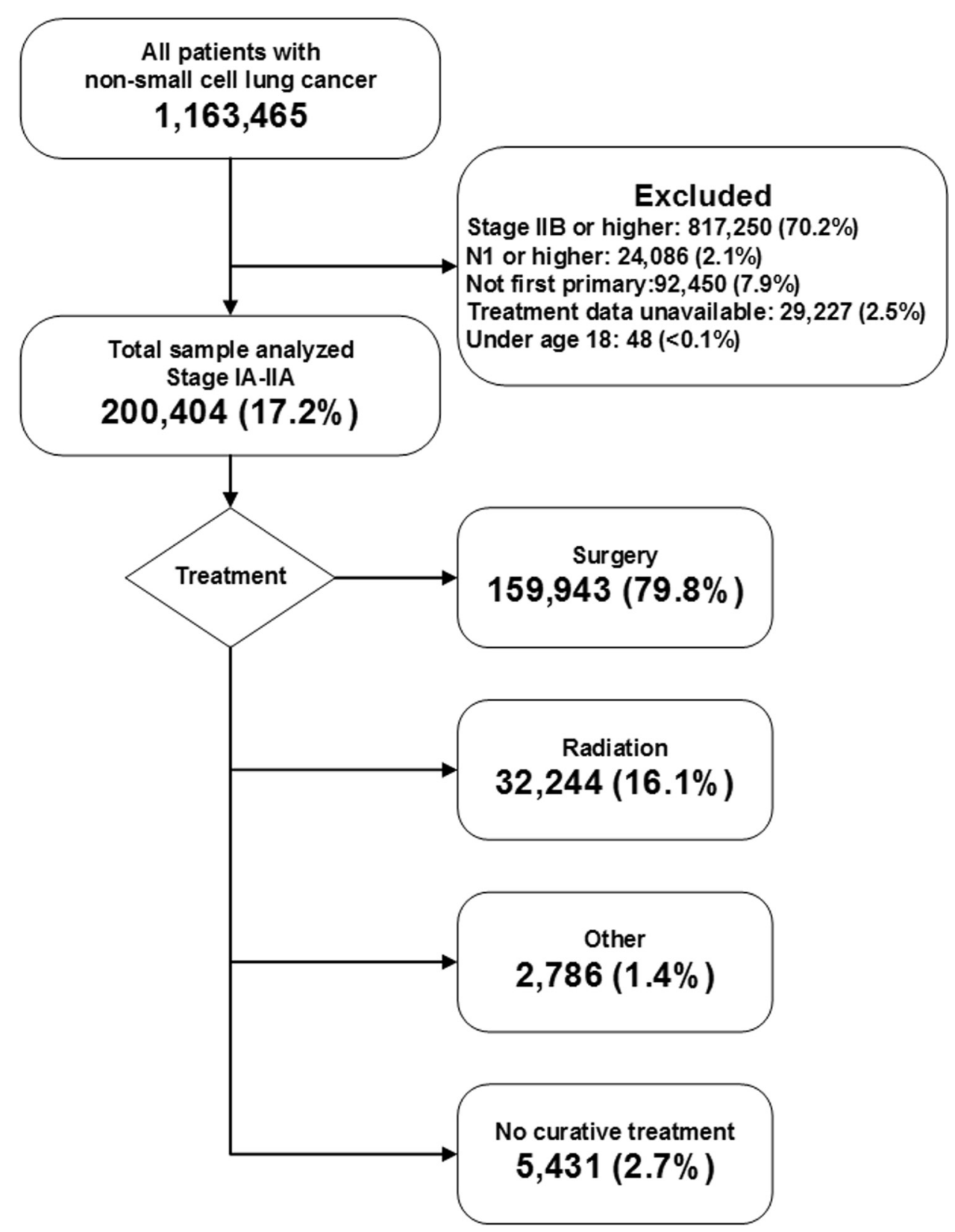

FIGURE 1. CONSORT diagram: Patients diagnosed with stage IA to IIA NSCLC from 2004 to 2013.

earlier-stage disease or adenocarcinoma histology. Conversely, uninsured patients or those with Medicaid as their primary payor were less likely to have received surgery.

\section{DISCUSSION}

In this time-trend analysis of NCDB data on patients diagnosed with potentially resectable stage IA to IIA NSCLC from 2004 to 2013, we aimed to determine the trend in therapy and factors associated with receipt of surgery in the modern era. We found that there has been an increase in both the use of radiation and the proportion of untreated patients. Concomitantly, we found a decrease in the rates of surgical resection over this same period.

The reason for the decreased use of surgery for earlystage NSCLC is unclear but may be related to changes in health policy, changes in patient preferences, or changes in referral patterns. The National Lung Screening Trial resulted in an update to the United States Preventative Services Task Force recommendation for lung cancer screening in $2013 .^{25}$ This may have resulted in increased detection of early-stage cancer in medically inoperable 
TABLE 1. Patient, tumor, and hospital characteristics for 200,404 patients diagnosed with stage IA to IIA non-small cell lung cancer from 2004 to 2013

\begin{tabular}{|c|c|c|c|c|c|c|c|c|}
\hline & \multicolumn{2}{|c|}{ Surgery $n=159,943$} & \multicolumn{2}{|c|}{ Radiation n $=32,244$} & \multicolumn{2}{|c|}{ Other treatment $n=2786$} & \multicolumn{2}{|c|}{ No curative treatment $n=5431$} \\
\hline & $\mathbf{n}$ & $(\%)$ & $\mathbf{n}$ & $(\%)$ & $\mathbf{n}$ & $(\%)$ & $\mathbf{n}$ & $(\%)$ \\
\hline Age, mean (SD), y & 67.0 & $(10.2)$ & 73.5 & $(9.3)$ & 69.8 & $(10.5)$ & 73.2 & $(10.4)$ \\
\hline \multicolumn{9}{|l|}{ Sex } \\
\hline Female & 85,293 & $(53.3)$ & 16,538 & $(51.3)$ & 1341 & $(48.1)$ & 2845 & $(52.4)$ \\
\hline Male & 74,650 & $(46.7)$ & 15,706 & $(48.7)$ & 1445 & $(51.9)$ & 2586 & $(47.6)$ \\
\hline \multicolumn{9}{|l|}{ Race } \\
\hline White & 127,909 & $(80.2)$ & 25,673 & $(79.9)$ & 2131 & (76.6) & 4113 & (75.9) \\
\hline Black & 23,518 & $(14.7)$ & 5473 & $(17.0)$ & 528 & $(19.0)$ & 940 & $(17.3)$ \\
\hline Hispanic & 3875 & $(2.4)$ & 484 & $(1.5)$ & 71 & $(2.6)$ & 195 & (3.6) \\
\hline Other & 4199 & (2.6) & 518 & (1.6) & 51 & (1.8) & 172 & (3.2) \\
\hline Academic Medical Center & 57,250 & $(36.2)$ & 10,894 & $(33.9)$ & 870 & $(31.6)$ & 1651 & $(30.6)$ \\
\hline \multicolumn{9}{|l|}{ Hospital volume* } \\
\hline$<153$ & 37,378 & $(23.4)$ & 8545 & $(26.5)$ & 854 & $(30.7)$ & 1858 & $(34.2)$ \\
\hline $153-271$ & 39,213 & $(24.5)$ & 8378 & $(26.0)$ & 676 & $(24.3)$ & 1227 & (22.6) \\
\hline $272-466$ & 41,127 & $(25.7)$ & 8026 & $(24.9)$ & 650 & (23.3) & 1092 & $(20.1)$ \\
\hline$>466$ & 42,225 & $(26.4)$ & 7295 & $(22.6)$ & 606 & $(21.8)$ & 1254 & $(23.1)$ \\
\hline \multicolumn{9}{|l|}{ Median income } \\
\hline Lowest quartile & 29,086 & $(18.5)$ & 7025 & $(22.1)$ & 621 & $(22.8)$ & 1307 & $(24.4)$ \\
\hline Second quartile & 38,514 & $(24.5)$ & 8949 & $(28.2)$ & 794 & $(29.1)$ & 1400 & (26.1) \\
\hline Third quartile & 42,354 & $(26.9)$ & 8394 & $(26.4)$ & 663 & (24.3) & 1418 & (26.4) \\
\hline Highest quartile & 47,460 & $(30.2)$ & 7391 & $(23.3)$ & 652 & (23.9) & 1238 & $(23.1)$ \\
\hline \multicolumn{9}{|l|}{ Education level } \\
\hline Lowest quartile & 26,282 & $(16.7)$ & 5748 & $(18.1)$ & 561 & $(20.5)$ & 1261 & $(23.5)$ \\
\hline Second quartile & 42,916 & $(27.3)$ & 9432 & (26.7) & 822 & (30.1) & 1600 & (29.8) \\
\hline Third quartile & 53,132 & $(33.7)$ & 10,556 & $(33.2)$ & 890 & (32.6) & 1620 & $(30.2)$ \\
\hline Highest quartile & 35,157 & $(22.3)$ & 6032 & $(19.0)$ & 462 & (16.9) & 883 & (16.5) \\
\hline Urban residence & 145,759 & $(94.3)$ & 29,337 & (93.8) & 2512 & $(93.5)$ & 4976 & (94.6) \\
\hline \multicolumn{9}{|l|}{ Charlson-Deyo Score } \\
\hline Score of 0 & 80,505 & $(50.3)$ & 17,806 & $(55.2)$ & 1487 & $(53.4)$ & 3122 & $(57.5)$ \\
\hline Score of 1 & 57,196 & $(35.8)$ & 9115 & $(28.3)$ & 827 & $(29.7)$ & 1419 & $(26.1)$ \\
\hline Score of $2+$ & 22,242 & $(13.9)$ & 5323 & $(16.5)$ & 472 & $(16.9)$ & 890 & (16.4) \\
\hline \multicolumn{9}{|l|}{ Histology } \\
\hline Adenocarcinoma & 96,090 & $(60.1)$ & 12,001 & $(37.2)$ & 1078 & $(38.7)$ & 2502 & $(46.1)$ \\
\hline Squamous cell & 43,490 & $(27.2)$ & 12,553 & $(38.9)$ & 932 & $(33.5)$ & 1903 & $(35.0)$ \\
\hline Other non-small cell & 20,363 & $(12.7)$ & 7690 & $(23.9)$ & 776 & $(27.9)$ & 1026 & $(18.9)$ \\
\hline \multicolumn{9}{|l|}{ Stage } \\
\hline IA & 98,573 & $(61.6)$ & 17,772 & $(55.1)$ & 1469 & $(52.7)$ & 2864 & $(52.7)$ \\
\hline IB & 52,021 & $(32.5)$ & 12,663 & (39.3) & 1117 & $(40.1)$ & 1912 & $(35.2)$ \\
\hline IIA & 9349 & $(5.9)$ & 1809 & (5.6) & 200 & $(7.2)$ & 655 & $(12.1)$ \\
\hline \multicolumn{9}{|l|}{ Year of diagnosis } \\
\hline 2004-2005 & 28,903 & $(18.1)$ & 4539 & $(14.1)$ & 520 & (18.7) & 334 & (6.2) \\
\hline 2006-2007 & 30,275 & $(18.9)$ & 5179 & $(16.1)$ & 595 & $(21.4)$ & 366 & (6.7) \\
\hline 2008-2009 & 32,329 & $(20.2)$ & 6474 & $(20.1)$ & 661 & (23.7) & 425 & (7.8) \\
\hline 2010-2011 & 33,870 & $(21.2)$ & 7406 & $(23.0)$ & 544 & $(19.5)$ & 2159 & (39.8) \\
\hline 2012-2013 & 34,566 & $(21.6)$ & 8646 & $(26.8)$ & 466 & (16.7) & 2147 & $(36.5)$ \\
\hline \multicolumn{9}{|l|}{ Insurance status } \\
\hline Medicaid or uninsured & 9826 & $(6.3)$ & 1648 & $(5.2)$ & 203 & (7.4) & 385 & (7.8) \\
\hline Private, Medicare, or Other & 147,137 & (93.7) & 30,137 & $(94.8)$ & 2533 & (92.6) & 4539 & $(92.2)$ \\
\hline
\end{tabular}

Missing values: $554(0.3 \%)$ missing race, $1844(0.9 \%)$ missing academic medical status information, $3138(1.6 \%)$ missing census data regarding income, 3050 (1.5\%) missing census data regarding education level; $6615(3.3 \%)$ missing data on urban/rural designation, $3996(2.0 \%)$ missing insurance data. $S D$, Standard deviation. *Hospital volume is defined as the number of cases of early-stage lung cancer diagnosed at each facility during the 10-year study period. 


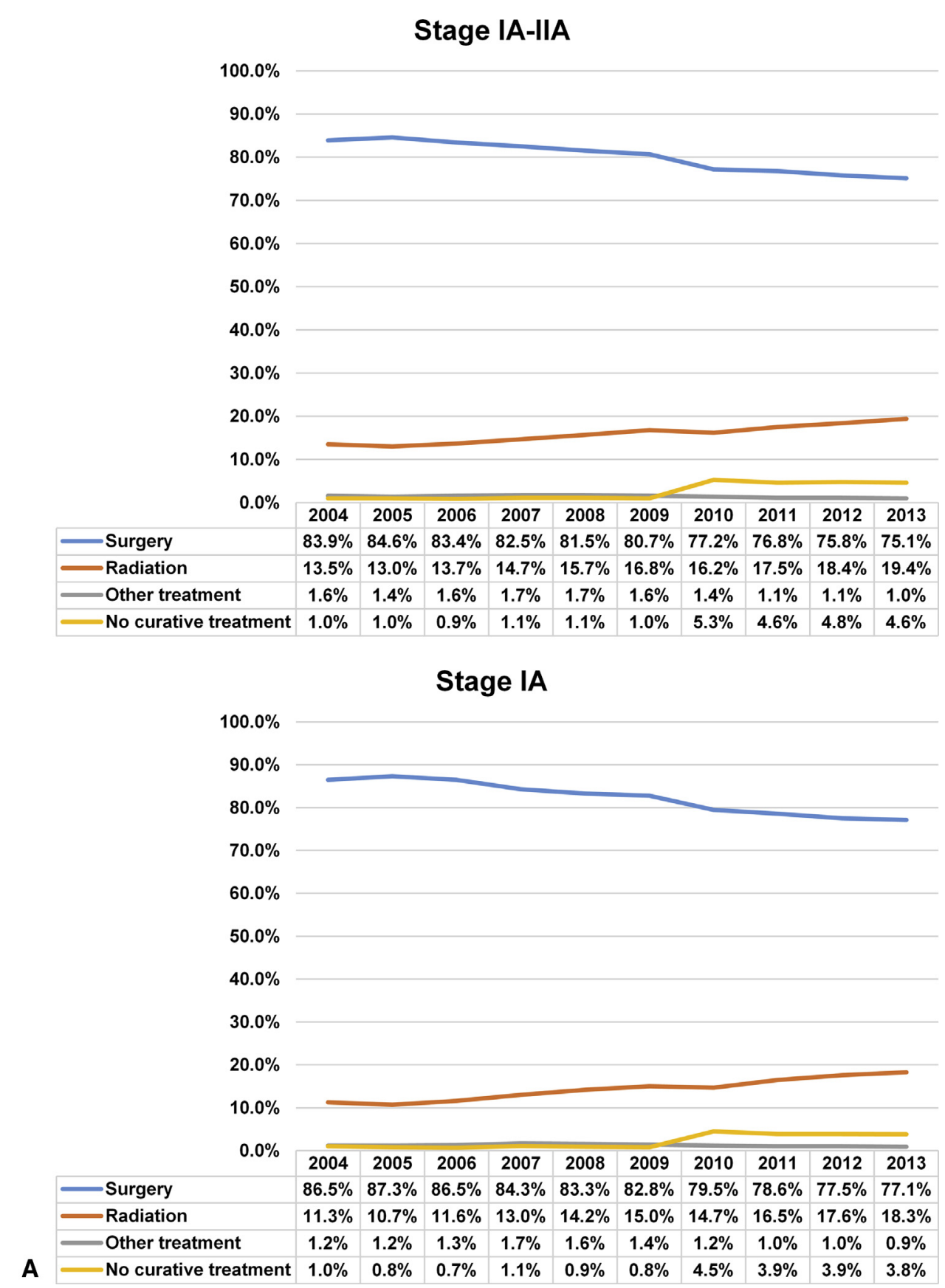

FIGURE 2. A and B, National trend in the management of NSCLC by stage IA to IIA from 2004 to 2013.

patients and therefore a decrease in the use of surgery. However, these recommendations were published in 2013 and are still not closely followed; recent data suggest less than $5 \%$ of eligible patients were screened according to guidelines in $2015 .^{24}$ Moreover, recommendations state that patients should be candidates for curative lung surgery to be eligible for screening. Therefore, we think it is unlikely that this health policy change explains our findings in their entirety.
There may be other factors influencing the treatment trends we report, including physician factors ${ }^{26}$ and patient and family care preferences. As a clinically abstracted dataset collected secondarily from medical records, the NCDB is limited to information documented in patients' medical charts. However, from the data available, we were able to show that most patients who did not receive surgery underwent radiation therapy, whereas a minority received no curative therapy. This is consistent with the corresponding 


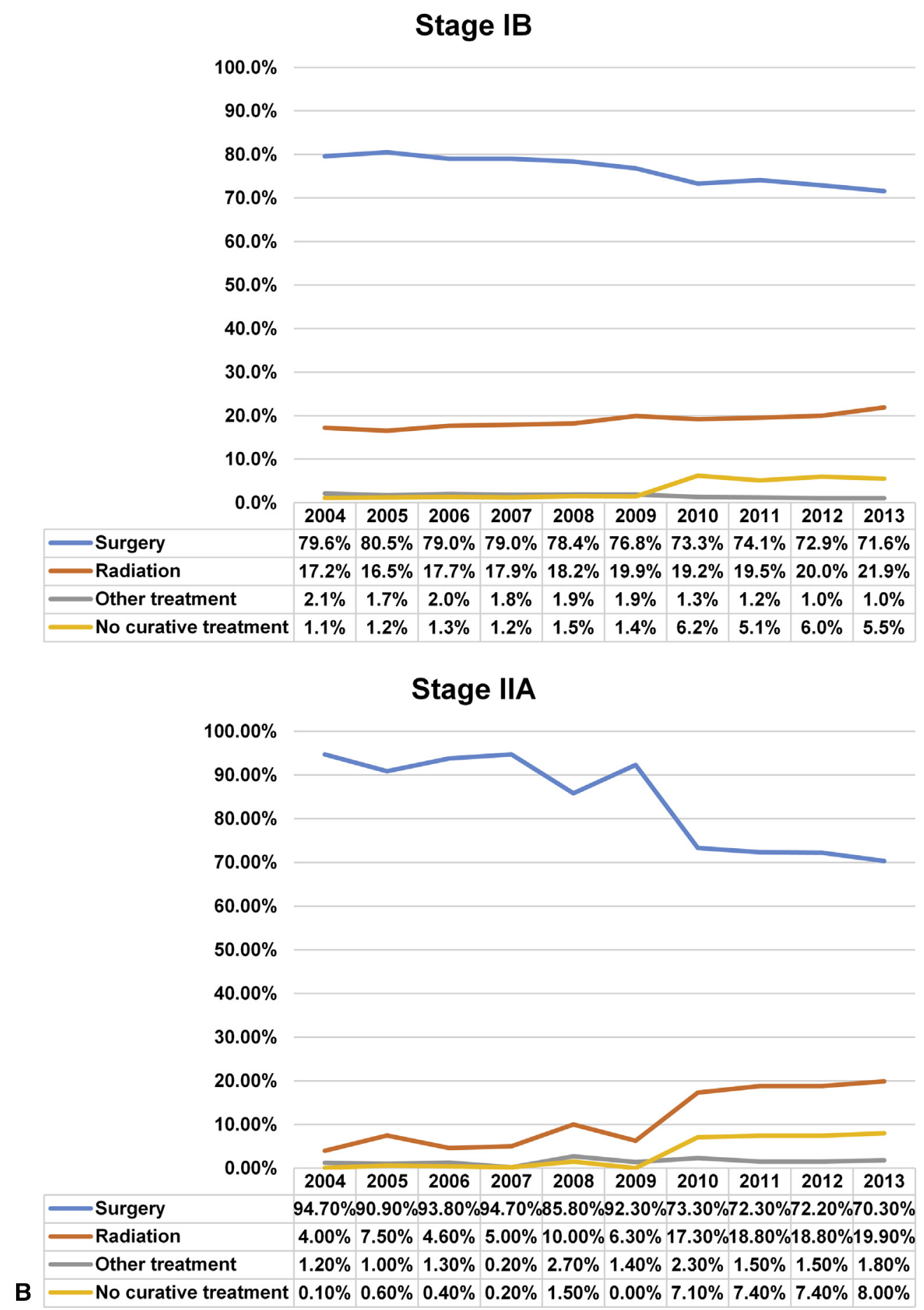

FIGURE 2. (Continued).

finding that the majority of patients who did not receive surgery were recorded as having an alternate therapy recommended as first line by one of their physicians. However, a subset of patients or families refused surgery even though it was recommended as primary treatment. Although there will likely always be a subset of patients for whom surgery does not align with their values, it is imperative that physicians ensure adequate education regarding the risks and benefits of all available treatment options.

There is limited research regarding patient preferences in lung cancer care worldwide, and specifically there are little published data examining treatment in the US population. 
TABLE 2. Treatment modality for patients with stage IA to IIA non-small cell lung cancer in a time frame before wide adoption of stereotactic ablative radiotherapy (2004-2005) compared with a time frame during which stereotactic ablative radiotherapy was widely used by radiation therapists (2012-2013)

\begin{tabular}{|c|c|c|c|c|c|c|}
\hline & \multicolumn{2}{|c|}{ 2004-2005 } & \multicolumn{2}{|c|}{ 2012-2013 } & \multicolumn{2}{|c|}{ Absolute difference } \\
\hline & $\mathbf{n}$ & $\%$ & $\mathbf{n}$ & $\%$ & $(\%[95 \% \mathrm{CI}])$ & $P$ value ${ }^{*}$ \\
\hline \multicolumn{7}{|l|}{ Stage IA-IIA } \\
\hline Surgery & 28,903 & $(84.3)$ & 34,566 & $(75.4)$ & $-8.8(8.3-9.4)$ & $<.0001$ \\
\hline Radiation & 4539 & $(13.2)$ & 8646 & (18.9) & $5.6(5.1-6.1)$ & $<.0001$ \\
\hline No curative treatment & 334 & $(1.0)$ & 2147 & $(4.7)$ & $3.7(3.5-3.9)$ & $<.0001$ \\
\hline Other (eg, chemotherapy) & 520 & (1.5) & 466 & $(1.0)$ & $-0.5(0.3-0.6)$ & $<.0001$ \\
\hline Total & 34,296 & $(100)$ & 45,825 & $(100)$ & & \\
\hline \multicolumn{7}{|l|}{ Stage IA } \\
\hline Surgery & 16,081 & $(86.9)$ & 22,982 & $(77.3)$ & $-9.6(8.9-10.3)$ & $<.0001$ \\
\hline Radiation & 2035 & $(11.0)$ & 5341 & $(18.0)$ & $7.0(6.3-7.6)$ & $<.0001$ \\
\hline No curative treatment & 161 & $(0.9)$ & 1143 & (3.8) & $3.0(2.7-3.2)$ & $<.0001$ \\
\hline Other (eg, chemotherapy) & 226 & $(1.2)$ & 267 & $(0.9)$ & $-0.3(0.1-0.5)$ & .0009 \\
\hline Total & 18,503 & $(100)$ & 29,733 & $(100)$ & & \\
\hline \multicolumn{7}{|l|}{ Stage IB } \\
\hline Surgery & 11,522 & $(80.1)$ & 8603 & $(72.3)$ & $-7.8(6.8-8.9)$ & $<.0001$ \\
\hline Radiation & 2423 & $(16.8)$ & 2497 & $(21.0)$ & $4.1(3.2-5.1)$ & $<.0001$ \\
\hline No curative treatment & 168 & $(1.2)$ & 687 & $(5.8)$ & $4.6(4.1-5.1)$ & $<.0001$ \\
\hline Other (eg, chemotherapy) & 279 & (1.9) & 122 & $(1.0)$ & $-0.9(0.6-1.2)$ & $<.0001$ \\
\hline Total & 14,392 & $(100)$ & 11,909 & $(100)$ & & \\
\hline \multicolumn{7}{|l|}{ Stage IIA } \\
\hline Surgery & 1300 & $(92.8)$ & 2981 & $(71.3)$ & $-21.5(19.5-23.4)$ & $<.0001$ \\
\hline Radiation & 81 & $(5.8)$ & 808 & $(19.3)$ & $13.5(11.8-15.2)$ & $<.0001$ \\
\hline No curative treatment & 5 & $(0.4)$ & 317 & (7.6) & $7.2(6.4-8.1)$ & $<.0001$ \\
\hline Other (eg, chemotherapy) & 15 & (1.1) & 77 & (1.8) & $0.8(0.1-1.4)$ & .0501 \\
\hline Total & 1401 & $(100)$ & 4183 & (100) & & \\
\hline
\end{tabular}

CI, Confidence interval.*Test of 2 proportions.

A prospective cohort study of US patients with NSCLC used a regression analysis of survey data to identify factors associated with the decision to undergo surgery: perception of communication and prognosis, older age, multiple comorbidities, and African-American race were associated with nonoperative treatment. ${ }^{27} \mathrm{We}$ were able to account for some of these factors in our analysis (age, comorbidity score, and race were available for all patients), but we did not have data regarding patient perceptions. A study of German patients with NSCLC suggested that patient preferences may be influenced by factors of interest to clinicians as well: progression-free survival and tumor-associated symptoms. ${ }^{28}$ However, these results may not be generalizable to the US population. Although there are limited data on family preferences for lung cancer care, a study of patients with lung and colon cancer in the United States suggests that the majority of patients reported at least some involvement of family in decision-making. ${ }^{29}$ Future survey-based or qualitative research in the United States is needed to define patient and family preferences for lung cancer care.

For clinical situations in which treatment technology is evolving faster than randomized clinical trials can be completed, treatment trends in the community do not always reflect the available level 1 data. ${ }^{15}$ Two European time-trend analyses of treatment trends in older patients with stage I NSCLC showed an increase in the rates of radiation treatment with a concomitant decrease in the proportion of untreated patients, but no change in the proportion of patients treated with surgery. ${ }^{30,31}$ These data suggest that SABR was being used appropriately for highrisk patients who otherwise would not be treated. In contrast, our analysis of patients of all ages with stage I to IIA NSCLC indicates that the increase in radiation was accompanied by a potentially inappropriate decrease in the proportion of patients treated with surgery. Qualitative or survey-based studies to better understand the reasons for this decrease in the rate of surgical therapy are needed.

Although current treatment guidelines do not recommend SABR as first-line treatment for moderate-risk patients with NSCLC, multiple observational studies have suggested therapeutic equipoise exists between SABR and surgery. A systematic review of studies published between 2006 and 2013 showed an equivalent 2-year overall survival between SABR and surgery. ${ }^{9}$ Likewise, a meta-analysis of articles published between 2000 and 2012 indicated no significant difference in overall survival between the 2 treatment strategies. ${ }^{10}$ 
TABLE 3. Multivariable logistic regression to identify factors associated with receipt of surgery, compared with radiation, from 2011 to 2013

\begin{tabular}{|c|c|c|c|c|c|c|}
\hline & Surgery & Radiation & OR $[95 \% \mathrm{CI}]$ & $\boldsymbol{P}$ & aOR $[95 \% \mathrm{CI}]$ & $\boldsymbol{P}$ \\
\hline Age, mean (SD), y & $66.8(10.3)$ & $73.6(9.3)$ & $0.93[0.93-0.93]$ & $<.001$ & $0.92[0.92-0.93]$ & $<.001$ \\
\hline \multicolumn{7}{|l|}{ Sex, n (\%) } \\
\hline Female & $28,540(55.3)$ & $6632(52.9)$ & Ref & - & Ref & - \\
\hline Male & $23,101(44.7)$ & $5904(47.1)$ & $0.91[0.87-0.95]$ & $<.001$ & $1.02[0.98-1.01]$ & .367 \\
\hline \multicolumn{7}{|l|}{ Race } \\
\hline White & $42,325(82.2)$ & $10,335(82.6)$ & Ref & - & Ref & - \\
\hline Black & $6123(11.9)$ & $1756(14.0)$ & $0.85[0.78-0.93]$ & $<.001$ & $0.77[0.70-0.85]$ & $<.001$ \\
\hline Hispanic & $1417(2.8)$ & $195(1.6)$ & $1.77[1.40-2.25]$ & $<.001$ & $1.81[1.34-2.44]$ & $<.001$ \\
\hline Other & $1651(3.2)$ & $223(1.8)$ & $1.81[1.51-2.16]$ & $<.001$ & 1.63 [1.35-1.97] & $<.001$ \\
\hline \multicolumn{7}{|l|}{ Median income } \\
\hline Lowest quartile & $9299(18.1)$ & $2652(21.2)$ & $0.69[0.62-0.76]$ & $<.001$ & $0.64[0.55-0.74]$ & $<.001$ \\
\hline Second quartile & $12,146(23.6)$ & $3396(27.2)$ & $0.70[0.63-0.77]$ & $<.001$ & $0.68[0.59-0.77]$ & $<.001$ \\
\hline Third quartile & $13,831(26.9)$ & $3291(26.3)$ & $0.82[0.76-0.89]$ & $<.001$ & $0.80[0.72-0.88]$ & $<.001$ \\
\hline Highest quartile & $16,190(31.5)$ & $3166(25.3)$ & Ref & - & Ref & - \\
\hline \multicolumn{7}{|l|}{ Median education } \\
\hline Lowest quartile & $8637(16.8)$ & $2251(18.0)$ & $0.91[0.83-1.00]$ & .050 & $1.01[0.90-1.14]$ & .816 \\
\hline Second quartile & $13,754(26.7)$ & $3582(28.6)$ & $0.91[0.85-0.98]$ & .009 & $1.00[0.92-1.08]$ & .956 \\
\hline Third quartile & $17,392(33.8)$ & $4137(33.1)$ & Ref & - & Ref & - \\
\hline Highest quartile & $11,702(22.7)$ & $2538(20.3)$ & $1.10[1.01-1.18]$ & .018 & $0.98[0.90-1.07]$ & .626 \\
\hline \multicolumn{7}{|l|}{ Hospital characteristic } \\
\hline Academic and high volume & $1475(2.9)$ & $342(2.7)$ & $1.05[0.83-1.32]$ & .700 & $0.87[0.70-1.08]$ & .205 \\
\hline Other academic & $17,836(35.0)$ & $4491(35.9)$ & $0.96[0.83-1.12]$ & .634 & $0.86[0.74-1.00]$ & .057 \\
\hline Community & $31,657(62.1)$ & $7683(61.4)$ & Ref & - & Ref & - \\
\hline \multicolumn{7}{|l|}{ Charlson-Deyo score } \\
\hline 0 & $25,822(50.0)$ & $6733(53.7)$ & Ref & - & Ref & - \\
\hline 1 & $18,251(35.3)$ & $3504(28.0)$ & $1.36[1.23-1.49]$ & $<.001$ & $1.44[1.31-1.58]$ & $<.001$ \\
\hline$\geq 2$ & $7568(14.7)$ & $2299(18.3)$ & $0.86[0.77-0.95]$ & .004 & $1.01[0.90-1.12]$ & .890 \\
\hline \multicolumn{7}{|l|}{ Histology } \\
\hline Adenocarcinoma & $32,081(62.1)$ & $5450(43.5)$ & Ref & - & Ref & \\
\hline Squamous cell & $13,041(25.3)$ & $5111(40.8)$ & $0.43[0.41-0.46]$ & $<.001$ & $0.48[0.46-0.51]$ & $<.001$ \\
\hline Other non-small cell & $6520(12.6)$ & $1975(15.8)$ & $0.56[0.51-0.61]$ & $<.001$ & 0.45 [0.41-0.49] & $<.001$ \\
\hline \multicolumn{7}{|l|}{ Stage } \\
\hline IA & $34,182(66.2)$ & $7689(61.3)$ & Ref & - & Ref & - \\
\hline IB & $12,914(25.0)$ & $3633(29.0)$ & $0.80[0.76-0.84]$ & $<.001$ & $0.90[0.85-0.95]$ & $<.001$ \\
\hline IIA & $4545(8.8)$ & $1214(9.7)$ & $0.84[0.77-0.92]$ & $<.001$ & $0.95[0.87-1.04]$ & .257 \\
\hline \multicolumn{7}{|l|}{ Year } \\
\hline 2011 & $17,075(33.1)$ & $3890(31.0)$ & $1.13[1.07-1.20]$ & $<.001$ & $1.15[1.09-1.22]$ & $<.001$ \\
\hline 2012 & $17,255(33.4)$ & $4181(33.4)$ & $1.06[1.01-1.12]$ & .024 & $1.07[1.01-1.13]$ & .017 \\
\hline 2013 & $17,311(33.5)$ & 4465 (35.6) & Ref & - & Ref & - \\
\hline \multicolumn{7}{|l|}{ Insurance status } \\
\hline Private, Medicare, or Other & $47,111(92.8)$ & $11,657(94.5)$ & Ref & - & Ref & - \\
\hline Medicaid or uninsured & $3677(7.2)$ & $673(5.5)$ & $1.35[1.23-1.49]$ & $<.001$ & $0.58[0.52-0.65]$ & $<.001$ \\
\hline
\end{tabular}

$O R$, Odds ratio; $C I$, confidence interval; $a O R$, adjusted odds ratio; $S D$, standard deviation.

The analysis was limited by the lack of direct comparison between groups, because the majority of articles included were reports on the survival of a cohort of patients treated only with surgery or a cohort of patients treated only with SABR. A propensity score-matched analysis of 128 patients with stage I or stage II NSCLC reported similar overall survival and 3-year freedom from progression between SABR and surgery. ${ }^{11}$ Moreover, in this dataset, the authors found superior locoregional control in patients treated with
SABR. However, a more recent propensity score-matched analysis of 102 patients with stage I NSCLC reported significantly better overall survival and disease-free survival in their surgical cohort, ${ }^{6}$ and a recent $\mathrm{NCDB}$ analysis of 15,343 healthy patients with stage I NSCLC reported significantly better overall survival in the surgical cohort. ${ }^{32}$

In an attempt to prospectively determine the comparative effectiveness of surgery versus SABR for patients with early-stage NSCLC, 3 randomized controlled trials were 
initiated; however, all 3 trials were closed early because of poor accrual. A recent pooled analysis of data from 2 of these trials, STARS and ROSEL, concluded that the data indicated therapeutic equipoise for patients with T1-T2a primary and node-negative disease, and the authors reported better overall survival in the SABR cohort. ${ }^{4}$ This study was limited by a small sample size, especially in long-term follow-up (only 27 patients were still at risk at 3 years). Although these trials were limited by poor accrual, they did add important insights for SABR protocols in future trials. One trial, SABRTooth (ISRCTN13029788), completed enrollment from centers in the United Kingdom in early $2017 .{ }^{33}$ A Veterans' Affairs-based trial, VALOR (NCT02984761), is active but not yet enrolling. ${ }^{34}$ In both of these studies, screening and enrollment will be performed by a pulmonologist and research nurse to reduce the bias introduced by thoracic surgeons and radiation oncologists. A US-based study, STABLE-MATES (NCT02468024), is enrolling candidates at high risk for surgery. The study is projected to complete data collection for the primary end point of 3-year overall survival in $2018 .{ }^{35} \mathrm{It}$ is our opinion that participation in these trials should be encouraged when possible.

\section{Study Limitations}

There are limitations to our study. First, data extracted from any database are subject to coding error. However, the NCDB data are collected by trained and audited abstractors, improving reliability. In addition, the data definitions are standardized. Thus, the effect of these differences is likely minimal. Second, all patients who had stage IA to IIA, and thus eligible for surgery based on stage, were evaluated. Because of the limitations of the NCDB data fields, we are unable to make further judgments on a patient's eligibility for surgical intervention. For example, no data for performance status or pulmonary function tests were available. Although the overall Charlson-Deyo score was available, more granular details about individual comorbidities were lacking. The surprising finding that people with 1 comorbidity were more likely to undergo surgery than patients with zero comorbidities highlights the potential problem with relying on a comorbidity score to accurately reflect the medical operability of a patient. Third, these data may be limited by selection bias because we analyzed only CoC-accredited hospitals that report to the NCDB. However, this file contains more than $80 \%$ of all lung cancer cases from a variety of hospitals that vary in type and size. ${ }^{16}$ Last, because $\mathrm{CoC}$ accreditation may change from year to year for individual facilities, the characteristics of the facilities represented in the database in 2004 may be substantially different from those in 2013. However, because of the large number and range of facilities, it is unlikely that treatment bias on the individual facility level would substantially affect our findings.

\section{CONCLUSIONS}

Our data demonstrate an overall decrease in the use of surgical therapy for lung cancer in early-stage disease. Because resection remains the standard of care for most patients with early-stage disease, these data indicate a potentially significant quality gap in the treatment of NSCLC. Further comparative effectiveness analyses are needed to compare both oncologic outcomes and patient-reported outcomes between surgical resection and SABR to define standards of care for all patient populations. The results of 3 large randomized trials comparing SABR and surgery for early-stage NSCLC are highly anticipated. In the meantime, qualitative or survey-based investigation of stakeholder perspectives may help to define the reasons for this quality gap in the treatment of patients with early-stage NSCLC.

\section{Webcast}

You can watch a Webcast of this AATS meeting presentation by going to: https://aats.blob.core.windows.net/ media/17AM/2017-05-01/RM302-304/05-01-17_Room302304_1454_Engelhardt.mp4.

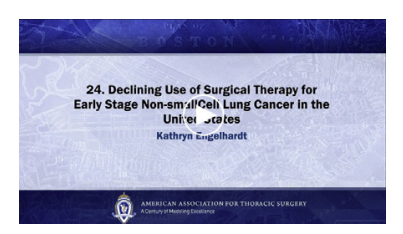

\section{Conflict of Interest Statement}

Authors have nothing to disclose with regard to commercial support.

\section{References}

1. Siegel RL, Miller KD, Jemal A. Cancer statistics. CA Cancer J Clin. 2016; 2016(66):7-30.

2. National Comprehensive Cancer Network. NCCN Clinical Practice Guidelines in Oncology: Non-Small Cell Lung Cancer. 2017; Version 4. Available at: https:// www.nccn.org/professionals/physician_gls/pdf/nscl.pdf. Accessed February 5, 2017.

3. Tipton K, Sullivan N, Bruening W, Inamdar R, Launders J, Uhl S, et al. Stereotactic Body Radiation Therapy Executive Summary. Rockville, MD: Agency for Healthcare Research and Quality.

4. Chang JY, Senan S, Paul MA, Mehran RJ, Louie AV, Balter P, et al. Stereotactic ablative radiotherapy versus lobectomy for operable stage I non-small-cell lung cancer: a pooled analysis of two randomised trials. Lancet Oncol. 2015;16:630-7.

5. Pan H, Rose BS, Simpson DR, Mell LK, Mundt AJ, Lawson JD. Clinical practice patterns of lung stereotactic body radiation therapy in the United States: a secondary analysis. Am J Clin Oncol. 2013;36:269-72.

6. Crabtree TD, Puri V, Robinson C, Bradley J, Broderick S, Patterson GA, et al Analysis of first recurrence and survival in patients with stage I non-small cell lung cancer treated with surgical resection or stereotactic radiation therapy. $J$ Thorac Cardiovasc Surg. 2014;147:1183-92.

7. Louie AV, Rodrigues G, Hannouf M, Zaric GS, Palma DA, Cao JQ, et al. Stereotactic body radiotherapy versus surgery for medically operable Stage I nonsmall-cell lung cancer: a Markov model-based decision analysis. Int J Radiat Oncol Biol Phys. 2011;81:964-73.

8. Shirvani SM, Jiang J, Chang JY, Welsh J, Likhacheva A, Buchholz TA, et al. Lobectomy, sublobar resection, and stereotactic ablative radiotherapy for earlystage non-small cell lung cancers in the elderly. JAMA Surg. 2014;149:1244-53. 
9. Solda F, Lodge M, Ashley S, Whitington A, Goldstraw P, Brada M. Stereotactic radiotherapy (SABR) for the treatment of primary non-small cell lung cancer; systematic review and comparison with a surgical cohort. Radiother Oncol. 2013;109:1-7.

10. Zheng X, Schipper M, Kidwell K, Lin J, Reddy R, Ren Y, et al. Survival outcome after stereotactic body radiation therapy and surgery for stage I non-small cell lung cancer: a meta-analysis. Int J Radiat Oncol Biol Phys. 2014;90:603-11.

11. Verstegen NE, Oosterhuis JW, Palma DA, Rodrigues G, Lagerwaard FJ, van der Elst A, et al. Stage I-II non-small-cell lung cancer treated using either stereotactic ablative radiotherapy (SABR) or lobectomy by video-assisted thoracoscopic surgery (VATS): outcomes of a propensity score-matched analysis. Ann Oncol. 2013;24:1543-8.

12. ClinicalTrials.gov. Randomized Study to Compare CyberKnife to Surgical Resection In Stage I Non-small Cell Lung Cancer (STARS); . Available at: https:// clinicaltrials.gov/ct2/show $/$ NCT00840749?term $=$ NCT00840749\&rank $=1$. Accessed April 3, 2017.

13. ClinicalTrials.gov. Trial of Either Surgery or Stereotactic Radiotherapy for Early Stage (IA) Lung Cancer (ROSEL); 2008. Available at: https://clinicaltrials.gov/ ct2/show/study/NCT00687986?term $=$ NCT00687986\&rank=1. Accessed April 3, 2017 .

14. Fernando HC, Timmerman R. American College of Surgeons Oncology Group Z4099/radiation therapy oncology group 1021: a randomized study of sublobar resection compared with stereotactic body radiotherapy for high-risk stage I non-small cell lung cancer. J Thorac Cardiovasc Surg. 2012;144:S35-8.

15. National Cancer Institute. NCI Levels of Evidence for Adult and Pediatric Cancer Treatment Studies;. Available at: https://www.cancer.gov/publications/pdq/ levels-evidence/treatment. Accessed February 5, 2017.

16. Bilimoria KY, Stewart AK, Winchester DP, Ko CY. The National Cancer Data Base: a powerful initiative to improve cancer care in the United States. Ann Surg Oncol. 2008; 15:683-90.

17. Edge S, Byrd DR, Compton CC, Fritz AG, Greene FL, Trotti A. American Joint Committee on Cancer. AJCC Cancer Staging Manual. 7th ed. New York: Springer; 2009.

18. Wang S, Wong ML, Hamilton N, Davoren JB, Jahan TM, Walter LC. Impact of age and comorbidity on non-small-cell lung cancer treatment in older veterans. $J$ Clin Oncol. 2012;30:1447-55.

19. Biswas T, Walker P, Podder T, Efird JT. Effect of race and insurance on the outcome of stage I non-small cell lung cancer. Anticancer Res. 2015;35:4243-9.

20. David EA, Cooke DT, Chen Y, Perry A, Canter RJ, Cress R. Surgery in highvolume hospitals not commission on cancer accreditation leads to increased cancer-specific survival for early-stage lung cancer. Am J Surg. 2015;210:643-7.

21. Hardy D, Liu CC, Xia R, Cormier JN, Chan W, White A, et al. Racial disparities and treatment trends in a large cohort of elderly black and white patients with nonsmall cell lung cancer. Cancer. 2009;115:2199-211.

22. Melvan JN, Sancheti MS, Gillespie T, Nickleach DC, Liu Y, Higgins K, et al. Nonclinical factors associated with 30-day mortality after lung cancer resection: an analysis of 215,000 patients using the national cancer data base. J Am Coll Surg. 2015;221:550-63.

23. Deyo RA, Cherkin DC, Ciol MA. Adapting a clinical comorbidity index for use with ICD-9-CM administrative databases. J Clin Epidemiol. 1992;45:613-9.

24. Jemal A, Fedewa SA. Lung cancer screening with low-dose computed tomography in the united states-2010 to 2015. JAMA Oncol. 2017;3:1278-81.

25. Force USPST. Final Recommendation Statement: Lung Cancer: Screening;. Available at: https://www.uspreventiveservicestaskforce.org/Page/Document/ RecommendationStatementFinal/lung-cancer-screening. Accessed February $14,2017$.

26. Hopmans W, Zwaan L, Senan S, van der Wulp I, Damman OC, Hartemink KJ, et al. Differences between pulmonologists, thoracic surgeons and radiation oncologists in deciding on the treatment of stage I non-small cell lung cancer: a binary choice experiment. Radiother Oncol. 2015;115:361-6.

27. Cykert S, Dilworth-Anderson P, Monroe MH, Walker P, McGuire FR, CorbieSmith G, et al. Factors associated with decisions to undergo surgery among patients with newly diagnosed early-stage lung cancer. JAMA. 2010;303:2368-76.

28. Muhlbacher AC, Bethge S. Patients' preferences: a discrete-choice experiment for treatment of non-small-cell lung cancer. Eur J Health Econ. 2015;16:657-70.

29. Hobbs GS, Landrum MB, Arora NK, Ganz PA, van Ryn M, Weeks JC, et al. The role of families in decisions regarding cancer treatments. Cancer. 2015;121: 1079-87.

30. Haasbeek CJ, Palma D, Visser O, Lagerwaard FJ, Slotman B, Senan S. Early-stage lung cancer in elderly patients: a population-based study of changes in treatment patterns and survival in the Netherlands. Ann Oncol 2012;23:2743-7.

31. Palma D, Visser O, Lagerwaard FJ, Belderbos J, Slotman BJ, Senan S. Impact of introducing stereotactic lung radiotherapy for elderly patients with stage I nonsmall-cell lung cancer: a population-based time-trend analysis. J Clin Oncol. 2010;28:5153-9.

32. Rosen JE, Salazar MC, Wang Z, Yu JB, Decker RH, Kim AW, et al. Lobectomy versus stereotactic body radiotherapy in healthy patients with stage I lung cancer. J Thorac Cardiovasc Surg. 2016;152:44-54.e49.

33. Snee MP, McParland L, Collinson F, Lowe CM, Striha A, Baldwin DR, et al. The SABRTooth feasibility trial protocol: a study to determine the feasibility and acceptability of conducting a phase III randomised controlled trial comparing stereotactic ablative radiotherapy (SABR) with surgery in patients with peripheral stage I non-small cell lung cancer (NSCLC) considered to be at higher risk of complications from surgical resection. Pilot Feasibility Stud. 2016;2:5.

34. Loganadane G, Martinetti F, Mercier O, Krhili S, Riet F-G, Mbagui R, et al. Stereotactic ablative radiotherapy for early stage non-small cell lung cancer: a critical literature review of predictive factors of relapse. Cancer Treat Rev. 2016;50: 240-6.

35. ClinicalTrials.gov. JoLT-Ca Sublobar Resection (SR) Versus Stereotactic Ablative Radiotheapy (SAbR) for Lung Cancer (STABLE-MATES). Available at: https://clinicaltrials.gov/ct2/show/NCT02468024. Accessed February 5, 2017.

Key Words: lung cancer, surgery, stereotactic body radiotherapy, health care utilization

\section{Discussion}

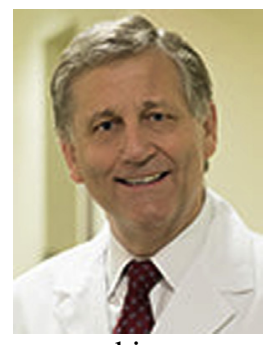

Dr Keith S. Naunheim (St Louis, Mo). As noted by Dr Engelhardt, the article is subject to the usual limitations found in a database analysis. Although it is an audited clinical database collected and collated by professional registrars, it does not include much of the detail that would be required to make clear many things we would like to know. There are no data regarding pulmonary function, cardiac status, or exercise capacity. It is impossible to determine if the surgery entailed anatomic or nonanatomic resection, and we cannot even be certain that the increased use of radiotherapy was due to more SBRT therapy as opposed to standard radiation therapy.

However, these drawbacks do not negate the value of the article. It is a look from 30,000 feet; it is a big picture. The authors have been able to look at this big picture over a decade and have noted a $6 \%$ shift in the type of treatment delivered to patients with early-stage lung cancer. There are many potential reasons why this shift occurred, including deterioration in patients' clinical status, which is undetected because you do not have all of the parameters necessary; a decreasing patient willingness to undergo even minimally invasive surgery; and finally a shift, whether valid or invalid, in referring physicians' attitudes regarding the efficacy of SBRT.

As a specialty, it is important for us as a group to be careful not to blindly reject this increased use of SBRT as simple 
ignorance or blatantly inappropriate use of what is undeniably a valuable new technology.

I warn of this possibility because it has happened before. At this very meeting in 1993 in New York, Dr Landreneau, who was in the room and may still be, and I and several of our colleagues were castigated by many of the leaders of thoracic surgery because of our use of a new and as yet undeveloped technology in the treatment of cancer. Our actions were labeled as unconscionable and bordering on malpractice. Our transgression was the use of thoracoscopy for the resection of lung metastasis. Then it was heresy; now it is standard of care. So it is imperative that we as a specialty not rush to judgment when dealing with this new technology. Especially with the onset of screening, there will be patients with 4-mm, 5-mm, 6-mm, 9-mm lesions and it's going to be a shame to do a lobectomy for that and maybe even a segmentectomy.

There will be place for SBRT for the treatment of earlystage lung cancer. It is our job and responsibility to help the radiation oncologists determine where that is and not have them disseminate it inappropriately as was done, for example, for percutaneous coronary intervention in coronary disease.

I have 2 questions for you. As you noted in your article, there were 2 publications from Europe with similar analyses regarding lung cancer management, and though they show that SBRT increased the rate of lung cancer going untreated, it did not decrease the rates of surgical resection in Europe. Can you provide any insight, whether it be clinical or sociopolitical, regarding the difference between the 2 continents?

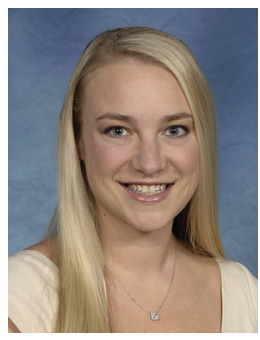

Dr Kathryn E. Engelhardt (Chicago, IIl). There are clearly a number of differences between the United States and European countries when it comes to health care. I think the most salient feature is the increased regionalization of treatment, specifically in The Netherlands, where the largest of those 2 studies was published. The Netherlands recently instituted minimum volume standards for surgical therapy. What that means is that now smaller hospitals are no longer performing cancer operations, and patients are getting shuttled to regional centers and being evaluated by a multidisciplinary team. In the United States, we do not have formal regionalization. I think that is an important distinction between the 2 countries.

Dr Naunheim. Many surgeons may conclude that the increased use of SBRT represents an inappropriate application of radiotherapy in an otherwise surgically curable patient subset. What steps do you believe we should take as a specialty to address the situation? Are multidisciplinary care conferences and clinical practice guidelines enough to turn the tide or are we doomed to repeat the experience of our cardiac colleagues, who endured a 15 -year period of inappropriate use of percutaneous coronary intervention in patients who would better have been served with surgical revascularization?

Dr Engelhardt. Clinical practice guidelines and multidisciplinary care conferences are definitely a place to start. Because of limitations of the database, we are unable to tell if patients who preferentially received SBRT in this patient cohort were evaluated by surgeons or not. I think the next steps are to drill down, look locally, and see if patients are being seen by a full complement of practitioners. To reiterate one of the points offered yesterday: Dr Boffa suggested that surgeons can become involved in the treatment planning for radiation therapy. I think that is an excellent way to stay involved and maintain our access to those patient populations.

Dr Royce Calhoun (Edgewood, Ky). That was a great article and a timely subject. I agree with what Keith said about the limitations of it. I have more of a comment. For me, this really segues into what Thor Sundt said in his presidential address about the team approach and the fact that as thoracic surgeons we really have so much more knowledge and involvement in these patients. I think it behooves all of us, whether we are busy or not, whether you are in academics but especially for those of us who are not, to reach out to the community and educate people and be very available.

My impression is that a lot of this stuff is done because it is expedient, it is sometimes inappropriate, and we find out after the fact people are deemed bad operative candidates, but they have never seen us. So people who we know very well, we could get through fairly well, are deemed inoperable by whomever.

As a Society, as a group of thoracic surgeons, we really need to do a better job of reaching out to people, educating them, and getting involved in this stuff earlier or it will get away from us and it will be like percutaneous coronary intervention.

The other thing is we need to participate in the trials that will help answer the question, which should demonstrate that surgery is superior. So if we don't do that, I think it's sort of a selfinflicted problem.

Dr Thomas M. Egan (Chapel Hill, NC). You have data on the number of patients who had surgery. Do you have data on the number of patients who had stereotactic radiation?

Dr Engelhardt. I'm not sure I understand.

Dr Egan. You had a graph that shows surgical treatment has gone down. Do you have any data on the use of stereotactic radiotherapy?

Dr Engelhardt. We have seen, essentially, a concomitant increase in the rate of radiation therapy, and it has gone up by about $7 \%$ over that time frame.

Dr Egan. So is it matching the decrease or just that fewer patients are being treated at all?

Dr Engelhardt. It is matching up slightly and actually increasing more than surgery is decreasing, because we also are seeing a decrease in the rate of untreated patients. 


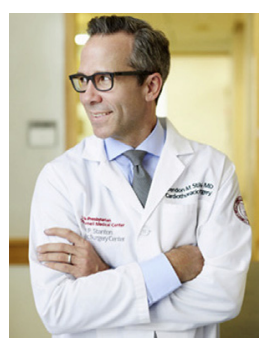

Dr Brendon Stiles (New York, NY). I was more optimistic when I saw it, because it looks like the absolute numbers are going up. I think if you just look at the percentages, it can be pretty disappointing. But is that just part of the NCDB? Have more centers accrued and added data or is there an actual absolute increase in the number of surgeries being done?

Dr Engelhardt. There is an absolute increase in the number of surgeries being done. The incidence of surgery has gone up slightly, as well as the number of centers included in the database. In the first year of our analysis, we had approximately 1100 participating centers, whereas that number increased by about 100 to 1200 by the end of our study time period.

Dr Stiles. That's an important distinction. It's not that we're losing patients. We just haven't done as good of a job capturing some of these new patients that radiation has. I think the older patients, the patients with other comorbidities, we just have to show, like the first article today, that we can do these cases safely with $0 \%$ mortality and little morbidity.

We have to get that word out there to everybody. I think it's really important. A bunch of us were just on a committee to review ASTRO guidelines that are being sent to the American Society of Clinical Oncology for publication in the Journal of Clinical Oncology about stereotactic radiation for early-stage cancer. When they first sent that to us from the ASTRO authors, in their article they talked about surgical mortality of $9 \%$ a $30 \%$ rate of major complications in these patients. We have to educate these people, too. Just like we educate ourselves, we have to educate the other doctors.

Dr Mark J. Krasna (Neptune, NJ). And we need to be on those committees.

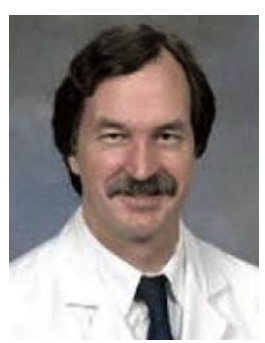

Dr Frank C. Detterbeck (New Haven, Conn). A couple of comments. Although this is an important study and phenomenon for us to understand well, I think we have to be careful about drawing conclusions. So I will echo a bit the question of is it the actual number of patients who are undergoing surgery that is going down or just the percentage, because the number of patients overall was going up and this increase is being carried by others.

To understand this better, I think we need to know how much SBRT is being done; has there been a stage shift? This predates screening coming along, but the number of computed tomography scans keeps going up, and that probably leads to more incidental pickup.

I think you could get some of that information, not from NCDB but other sources; I think if we can show a correlation with some of those things, we would have a better understanding of what this actually means. So that is just a suggestion.

Dr Engelhardt. It will be interesting to investigate this trend in additional datasets.

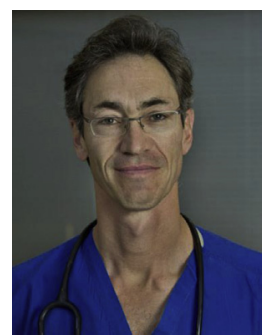

Dr Joseph B. Shrager (Stanford, Calif). I participated in a debate with a radiation oncologist at the American Thoracic Society in a roomful of pulmonologists about a year ago. It was very interesting. We all see this in our tumor boards, but the radiation oncologists are out there quoting that infamous Lancet Oncology article as though it proves definitively that SBRT is better than surgery. That article took 2 tiny failed randomized trials, with all sorts of flaws in each one, and brought them together in a completely unscientific and inappropriate way to supposedly show SBRT is better than surgery. So there are radiation oncologists out there quoting this stuff.

Everyone in this room should know that article better than the people they have to discuss this with, and they should read all of the editorials that have been written about it. You have to be able to debunk this stuff, and it's easy to debunk if you have read it and thought about it. We have to be able to do that or we are going to lose this. So it's just really important that we know the data and the arguments against this, and we fight the fight.

Dr Krasna. What is the article, Joe?

Dr Shrager. It's in Lancet Oncology. I can't remember the name of the first author.

Dr Engelhardt. It's Joe Y. Chang, 2015.

Dr Shrager. Right. So it combined the STARS trial, which was stopped after something like 20 patients.

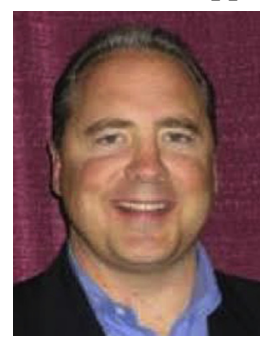

Dr Daniel L. Miller (Marietta, Ga). Twenty-six percent of patients did not have a tissue diagnosis.

Dr Shrager. We could sit here all day and talk about the problems with the studies. We don't have time to go through each and every one of them. But it's totally false, it's totally inappropriate science. Let alone in a Lancet series journal, it shouldn't even have been published in a throwaway journal, and this is the strongest stuff that the radiation oncologists think they have. So you have to delve into that.

Dr Paul H. Schipper (Portland, Ore). We know 30\% to $50 \%$ of lung cancer surgery is performed by general surgeons, but those surgeons are retiring, and the newly trained general surgeons are not being trained in thoracic and not doing it.

We also know that most of us work in urban medical centers, and what I am wondering if this trend, if you can tell me, is the same in a rural hospital versus our own house, an urban medical center, or if this might be an access to 
care issue? A radiation oncologist can set up a practice in a rural hospital and do quite well where many of us cannot; there's just not enough to do.

Dr Engelhardt. We did include facility characteristics in our regression model, which includes volume, academic status, and urban/rural designation. While we did not look at those as separate subsets, the characteristics of treating facilities for surgical cases was similar to that of SBRT cases.

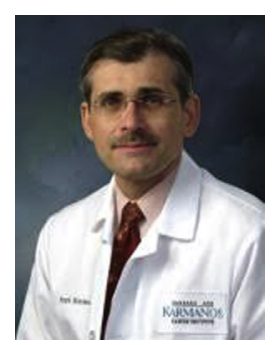

Dr Frank A. Baciewicz (Detroit, Mich). I want to make a pitch here for the multidisciplinary tumor boards at all of these places, because I think what happens is at a lot of places the radiation oncologist sees the patient, but if the patient gets to a multidisciplinary tumor board, you may not have as much surgery being done. So I just put a pitch for the multidisciplinary tumor boards and to participate in those things at your institution.

Dr Miller. If you look at the institutions in the study, and even mine, the highest profit margin procedure for radiation oncologists is SBRT right now, because of short treatment time, but full-dose radiation. So what may be driving a lot of this is profit to the institution? If the patient is seen in a community-based setting, like you were saying, the patients are usually not seen in a multidisciplinary clinic to determine treatment, and they may be referred directly to a radiation oncologist because of the increased profits to their institution.

Dr Krasna. I see that would be driving referrals, but I hope that the right thing is being done for patients. If you looked at the cohort of patients who received surgery versus the cohort of patients who received SBRT, what was the median age? Were they the same or was the SBRT group higher? You should have that information, right?

Dr Engelhardt. Yes, we do have that information. The patients who received SBRT were slightly older, their mean age was 74 years, and the mean age for patients receiving surgery was 67 years.

Dr Krasna. So not a huge difference. We're not talking about 85-year-olds versus 72-year-olds?

Dr Engelhardt. Right.

Dr Krasna. So the summary is we have to educate, we have to be at the meetings, we have to be at the radiation meetings as a force, and we have to be on any of the panels that are outside of our Society. 
80

70

$50 \longrightarrow$ IA

$$
\rightarrow \text { IB }
$$

40

$\rightarrow$ IIA

(4)

$\rightarrow$ IIB or higher

30

20

10
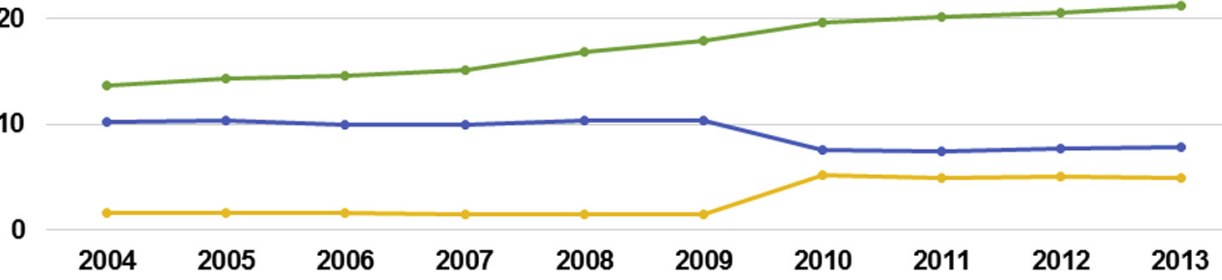

FIGURE E1. The proportion of early stage non-small cell lung cancers compared with the overall number of lung cancer diagnoses 2004 to 2013. 